\title{
Uma ciência do psiquismo é possível? A psicologia empírica de Kant e a possibilidade de uma ciência do psiquismo
}

Amandio Gomes ${ }^{\star}$

\section{RESUMO}

A questão da cientificidade da psicologia é discutida a partir da epistemologia kantiana. Apesar de recusar-lhe o título de legitimidade científica, Kant situou o objeto da psicologia no campo da experiência, os fenômenos do sentido interno. A psicologia deixa de ser disciplina metafísica para tornar-se empírica, abrindo caminho para a psicologia experimental. Mas nossa discussão propõe como orientação para pensar a cientificidade da psicologia a "Antropologia Pragmática" de Kant, na qual a subjetividade deixa de ser entendida como interioridade, como sujeito empírico em sua passividade, para considerar o sujeito como atividade cujo exercício se faz encarnar no mundo externo, definindo a existência do homem a partir de sua conduta na história.

Palavras-chave: Epistemologia da psicologia. Psicologia empírica. Kant. Antropologia pragmática.

\section{A science of the psychism is possible? Kant's empirical psychology and the possibility of a science of the psychism}

\begin{abstract}
The question regarding psychology and its scientific legitimacy is approached from the point of view of kantian epistemology. In spite of denying psychology scientific legitimacy, Kant placed the object of psychology within the field of experience, the phenomena of internal sense, paving the road for the experimental psychology of the nineteenth century. But it's in Kant's "Anthropology from the Pragmatic Point of View" that we find an orientation for psychology. Instead of the empirical subject in his passivity, understood as interiority, psychology would consider the subject as activity which is incarnated in the external world, defining the existence of man through his conduct in history.

Keywords: Epistemology of psychology. Empirical psychology. Kant. Pragmatic anthropology.

^ Professor do Depto. de Psicologia Geral e Experimental Instituto de Psicologia - UFRJ - Endereço: Rua Pires de Almeida, 26/101 Laranjeiras - Rio de Janeiro 22240-150 E-mail: amandiogomes@uol.com.br
\end{abstract}




\section{Psicologia racional e PSicologia empírica}

Nossa questão é inicialmente histórica, pois partimos de um veto formulado pelo filósofo alemão Emanuel Kant no século XVIII, no contexto de sua teoria do conhecimento, relativo à constituição da psicologia empírica como ciência. Interessa-nos aí apresentar as razões que levaram esse filósofo - que pretendeu estabelecer as condições de possibilidade de toda ciência - a negar à psicologia o título de legitimidade científica.

Entretanto, o "veto" kantiano à psicologia, não inibiu de fato os vários empreendimentos que visavam a uma ciência do psiquismo. Na verdade, já a partir do início do século XIX o que vemos é o florescimento de uma psicologia empírica que era, à sua maneira, uma continuação da revolução que fez surgir o mundo moderno. Essa "Revolução Copernicana", que situou o homem no centro do universo, localizando nele as condições de possibilidade do conhecimento, ${ }^{1}$ deu-se não apenas à medida que considerou as condições relativas ao entendimento humano (preocupação evidente no racionalismo cartesiano e na filosofia transcendental de Kant), mas também à medida que investigava sua encarnação, na especificidade de sua constituição fisiológica, ${ }^{2}$ como demonstram nos trabalhos em psicofísica da primeira metade do século XIX. Na verdade, é principalmente seguindo esse esforço inicial de se produzir uma ciência do psiquismo, ainda no âmbito da fisiologia, que surgirá a psicologia experimental, com W. Wundt, no final do século XIX.

Apesar do veto acima mencionado, Wundt, que se dizia kantiano, funda a psicologia experimental rejeitando justamente a exigência de Kant a todo saber que se pretenda científico: a possibilidade de formalizar matematicamente seu objeto, conforme os princípios a priori do entendimento humano.

A constatação de Ebbinghaus de que "a psicologia tem um passado longo mas uma história breve" (EBBINGHAUS, 1950 apud BORING, 1978), feita no final do século XIX, é válida ainda hoje. Em seu longo "passado" a psicologia sempre foi a "ciência" da alma, como indica sua etimologia. Já em Aristóteles, cuja teoria do conhecimento realista opõe-se à metafísica do supra-sensível, a psicologia era a ciência da "forma" do corpo, isto é, de sua organização. Em outras palavras, embora não fosse uma realidade supra-sensível, a alma se distinguia do corpo, sendo dele sua forma, seu princípio de organização.

A "história" da psicologia nos revela um esforço de distinção entre uma ciência do psiquismo e uma psicologia metafísica, dogmática, ao lado da teologia e da cosmologia. Denominada "Psicologia Racional" pela tradição metafísica vigente até o século XVIII, ela tinha por objeto a alma ou substância espiritual, cuja realidade supra-sensível não poderia então permitir uma abordagem pela via da experiência. E era justamente a experiência, a experiência sensível, comum a todos os homens, que garantiria a possibilidade de a psicologia, como a física, ser objetiva. Seguindo a "Revolução Copernicana", a psicologia devia poder se sustentar na experiência e constituir-se, assim, como conhecimento objetivo, e abandonar as ilusões metafísicas da Psicologia Racional, que podiam se sustentar ape- 
nas nos dogmas da filosofia escolástica. Claramente a psicologia, desde o século XIX até nossos dias, é então psicologia experimental, distinta da psicologia metafísica pelo voto de constituir-se como ciência. "Psicologia Científica", era o que significava para Wundt a Psicologia Experimental, cuja história se inaugura simbolicamente com seu primeiro laboratório em Leipzig em 1879, o Psychologisches Institut.

Cabe lembrar que a distinção entre psicologia racional e psicologia empírica já havia sido feita por Christian Wolff - cuja obra Kant conhecia tão bem e que por muito tempo foi tema de seus cursos. Mas foi o próprio Kant que, apesar do veto posterior, viria a preparar efetivamente o solo para a psicologia experimental. Foi esse filósofo da remota Könisberg que mostrou que a psicologia podia de fato se apresentar como sustentada na experiência sensível. No lugar de uma alma transcendente, fora do mundo da experiência, o objeto da psicologia de Kant é um "eu" empírico, ou fenomenal, um objeto na mesma série dos objetos na natureza.

Da longa discussão relativa à psicologia empírica em Kant interessa-nos ressaltar que o eu empírico de Kant é objeto de uma experiência interna (temporal), que na verdade depende do trabalho de síntese realizado pelo "eu" ou "sujeito transcendental" na constituição da experiência dos objetos no espaço, e da própria objetividade científica de um modo geral. Ou seja, a experiência interna que temos do nosso "eu" é a experiência da aplicação "no tempo" das regras necessárias e universais que tornam possíveis não só o conhecimento objetivo, mas a mera experiência dos objetos (os objetos espaciais, externos, diante dos quais, por exemplo, eu, agora e aqui, me encontro), e que são regras "atemporais" como o próprio sujeito do conhecimento ou, em termos kantianos, o "sujeito transcendental". No lugar da alma, a psicologia passou a ter, a partir de Kant, uma realidade empírica, um conteúdo sensível ao qual poderia se remeter, no esforço de se constituir como ciência. Contra a epistemologia empirista, que pretendia explicar o conhecimento pelo sujeito empírico ou "psicológico" e as ligações que ele era capaz de realizar (pelo "hábito"), Kant mostrara que esse sujeito psicológico não só era insuficiente, mas também que era uma realidade, digamos, derivada, produzida a partir do trabalho impessoal, não-psicológico, do "sujeito transcendental" - mesmo que a experiência de si e dos estados subjetivos internos, no tempo, se nos apresente psicologicamente como primeira. Diante do problema do conhecimento e suas condições de possibilidade, transcendentais e não-psicológicas, a psicologia empírica não tem mais nenhuma relevância. Ou seja, como tentativa de explicar o conhecimento, a psicologia era um grande equívoco, porque assumia o "eu" empírico ou psicológico como condição da objetividade quando, na verdade, é condicionado pelo "sujeito transcendental", em seu trabalho de constituição da objetividade.

O "eu" da psicologia, o sujeito empírico ou psicológico era apenas uma espécie de by-product na produção da objetividade, distinguindo-se do "eu" transcendental como uma espécie de resíduo do trabalho de objetivação, como aquilo que resta irredutivelmente inobjetivável, enfim, subjetivo. Vale lembrar que os fenômenos externos, espaciais, são também necessariamente subjetivos, 
internos, temporais. O que significa dizer que a experiência dos objetos é sempre a experiência de alguém em particular, de um "eu" ou sujeito empírico, e, portanto, também subjetiva. O vermelho da maçã é externo, uma qualidade que predicamos ao objeto maçã, mas a sensação do vermelho é dada internamente para um sujeito empírico, num dado momento no tempo, o momento em que o sujeito olha para a maçã que está na mesa à sua frente, depois de sentir o cheiro do bolo que a vizinha está assando, de sentir saudade do bolo de sua mãe, de sentir fome, antes de lembrar que não almoçou. Tudo isso além de perceber o objeto externo maçã. Mas, enquanto todo fenômeno externo é também necessariamente interno, nem todo fenômeno interno é também externo, como o vermelho que o mesmo sujeito "vê" no sonho ou seu sentimento de saudade do bolo que sua mãe fazia, que são exclusivamente subjetivos. A psicologia, portanto, teria por material apenas esses estados unicamente internos, subjetivos, enquanto os fenômenos espaciais são os materiais com os quais trabalha a física.

Mesmo assim, isto é, mesmo que a psicologia tenha sido condenada por Kant ao subjetivismo, um passo importante foi dado para sua constituição como disciplina experimental. Na psicologia empírica de Kant, o problema clássico da união da alma imaterial com o corpo perde o sentido, já que o mundo interno, subjetivo, e os objetos físicos se situam no mesmo plano da experiência, no plano dos fenômenos. No lugar de uma alma transcendente, fora da natureza (metafísica) como na Psicologia Racional, a psicologia empírica tinha por objeto um "eu" empírico e seus estados, dos quais se tem uma experiência, no tempo (e só no tempo). Assim, dados apenas no sentido interno os fenômenos são subjetivos, enquanto os fenômenos objetivos são aqueles dados no sentido externo. A psicologia passava, então, a ter um objeto que podia ser abordado experimentalmente, podendo, assim, almejar a cientificidade. Mais de um século depois, essa conclusão da discussão sobre o eu empírico e a psicologia racional na Crítica da Razão Pura (KANT, 1997) (4ํ Paralogismo, Dialética Transcendental), reaparece quase literalmente no comentário de Th. Ribot sobre o significado corrente da palavra "psicologia" na França, Alemanha e Inglaterra:

A psicologia da qual se trata aqui será então puramente experimental: ela só terá por objeto os fenômenos, suas leis e suas causas imediatas; ela não se ocupará nem da alma nem de sua essência, pois essa questão, estando para além da experiência e fora da verificação, pertence à metafísica (RIBOT, 1907, p. 33-34).

\section{O "VETo" KANTIANO}

Mas desse eu fenomenal, objeto da psicologia empírica, poderíamos ter um conhecimento objetivo tal como aquele que temos dos outros objetos da natureza? $\mathrm{Ou}$, ainda, o eu que se nos apresenta no sentido interno (cuja forma é o tempo), como mundo interior, pode ser conhecido do mesmo modo que conhecemos os objetos do sentido externo - (cuja forma é o espaço) - do mundo exterior? A reposta de Kant (1989) a essa pergunta é negativa, como vemos nos Primeiros Princípios Metafísicos da Ciência da Natureza. A psicologia não poderia jamais igualar-se à física, ciência dos corpos no espaço. Seu objeto se dá apenas no tem- 
po, e por ser unicamente temporal, não poderia ser matematizado. Poderíamos, no máximo, compreendê-lo como uma linha reta, representando o curso ininterrupto dos estados internos desse eu, um devir incessante de modificações subjetivas, sem que se pudesse aí encontrar algo que permaneça, como é o caso dos objetos espaciais. Em resumo, a formalização matemática, necessária à constituição da objetividade científica, e que para Kant repousava sobre princípios a priori, não era possível no caso da psicologia empírica.

Assim, o psiquismo com o qual se ocupará a psicofísica já não será mais a alma da Psicologia Racional, e, com isso, em lugar de discutir a relação entre o mundo material e a imaterialidade da alma, essa nova disciplina empenhou-se em mostrar que havia uma relação entre o mundo físico (o fenômeno externo do estímulo físico) e o mundo mental (o fenômeno interno ou mental da sensação), como fizeram Weber e depois Fechner. Mas mostrar que há leis que regem a relação do mundo mental com o mundo físico e que tais leis se devem à constituição psíquica do homem não é suficiente para que se tenha propriamente uma ciência do psiquismo. Mesmo que se tivesse conseguido avançar nesse projeto, ainda assim a questão central não teria sido respondida, pois não é a relação entre os elementos do mental com os elementos do mundo físico que interessaria a uma ciência do mental. E Wundt, por sua vez, atendo-se apenas ao mental, àquilo que podia ser acessível em primeira pessoa, não consegue ir muito longe: os resultados das pesquisas experimentais realizadas segundo o método introspeccionista não garantiam nenhuma objetividade. Faltava o fundamental: estabelecer relações matemáticas entre os elementos ou estados mentais, internamente. Como Kant já o havia mostrado, não poderia jamais haver uma psicologia matemática, como há uma física matemática. Por isso, diz Kant (1989, p. 33), “a psicologia nunca pode ser mais que uma doutrina histórica da natureza do sentido interno e, como tal, tão sistemática quanto possível, ou seja, uma descrição natural da alma, mas nem sequer uma doutrina psicológica experimental".

Da alma substancial da psicologia racional ao "eu" fenomenal da psicologia empírica o progresso em direção a uma ciência do psiquismo foi enorme, pois o objeto da psicologia desceu do céu transcendente da metafísica para o solo fenomenal da ciência. Mas o domínio que aí ocupava esse objeto resistia à objetivação.

\section{A metafísica da natureza, a CIÊNCIA E A PSICOlogia}

Desde a física newtoniana a ciência avançou muito mais do que poderia conceber Kant. Seu projeto de fundamentar a ciência, estabelecendo de uma vez por todas o critério racional que demarcaria o campo de sua legitimidade não pode se sustentar. Os avanços da ciência dispensaram inteiramente o conhecimento $a$ priori que deveria, segundo Kant, sustentar toda ciência. A parte pura que ele julgava ser necessária para sua formalização matemática talvez não fosse mais do que uma tentativa de explicar o conhecimento científico e seu progresso por uma razão universal e eterna, por uma "Metafísica da Natureza", como ele próprio chamava. Talvez se tratasse ainda, em sua teoria do conhecimento, de restabelecer os direitos da Metafísica substituindo aquela que se tornou caduca, com sua apos- 
ta insensata na transcendência, pela instauração, mediante uma razão conforme os limites da finitude humana, uma razão razoável, na forma de um conjunto de condições necessárias e universais a todo conhecimento.

Evidentemente, a pretensão kantiana de fundamentar a ciência sobre as bases de uma metafísica renovada não pode ser entendida fora do contexto histórico do século XVIII. Hoje ninguém duvida que a teoria do conhecimento de Kant e, sobretudo sua exigência de fundamentação da ciência perderam o sentido. Seu projeto de fundamentação em uma metafísica do a priori pode ter servido apenas para atravancar senão o surgimento, pelo menos o progresso da ciência, que acabou mostrando que uma fundamentação metafísica era ao mesmo tempo impossível e desnecessária. ${ }^{3}$

Mas será que a impossibilidade de se estabelecer limites a priori ao campo da investigação científica teria permitido à psicologia superar o veto kantiano, garantindo a ela algum lugar ao lado da física e da química, por exemplo ${ }^{4} \mathrm{Ou}$, então, pelo menos, considerando o alargamento do campo da objetividade, no qual os fenômenos não permitem uma formalização matemática rigorosa como na física, no qual a ciência não é tão "dura”, será que aí se poderia acomodar a psicologia?

A história da física ou da química não deixa dúvida quanto ao seu estatuto científico. Sem sequer questionar-se sobre esse ponto, o físico não se vê obrigado a mostrar o caráter científico de seu trabalho. O progresso da física é expressão de um avanço cada vez maior em sua objetividade. Mas o que dizer da história da psicologia? O que mostra Foucault (1994, p. 137 ss.) em relação às escolas clássicas vale ainda para os "programas de pesquisa" em psicologia na atualidade (sobretudo na área das ciências da cognição) que se confrontam sempre com o intuito de mostrar, não a parcialidade de um conhecimento objetivo já conquistado ("um erro científico") e sua ampliação, mas as "ilusões" de que são vítimas as escolas antagonistas, e sua superação no sentido da descoberta de uma verdade do homem.

Para explicitar o que nos parece decisivo, diremos que a psicologia não progride porque seu objeto - o psiquismo - não é passível de uma formalização que o retire do contexto social e histórico em que se encontra. Evidentemente, toda ciência certamente depende de condições, digamos, exteriores ao trabalho de pesquisa científica. A física atômica, por exemplo, não pode avançar sem os recursos, e toda espécie de estímulos provenientes de interesses políticos, militares, econômicos e etc. relativos a uma determinada situação histórica. São eles que, por exemplo, mantêm os laboratórios e os salários dos pesquisadores envolvidos. Mas as aplicações determinadas pela política ou pela economia, os inúmeros interesses específicos de um dado contexto não alterarão as forças de coesão das partículas atômicas estudadas pelo físico. O objeto construído pela física permanece mesmo que desapareçam os interesses que sustentaram sua pesquisa. O átomo e seu núcleo podem tornar-se desinteressantes de muitas maneiras mas mantêm-se como objeto físico. "As conclusões da ciência são determinadas pelo mundo físico e não pelo mundo social" (CHALMERS, 1994, p. 113). Seria esse também o 
caso da psicologia? O que restaria do psiquismo, fora das condições históricas em que se realizam as pesquisas científicas em psicologia?

\section{A DIREÇÃo dA ANTROPOlOGIA PRAGMÁtiCA}

Kant, ainda que por más razões, negou à psicologia a legitimidade científica que desde o início de sua pesquisa experimental ela buscou, sem sucesso. No entanto, o problema de sua cientificidade não é facilmente desqualificável. E é no próprio Kant, ainda no século XVIII, que encontramos uma orientação para pensar uma resposta positiva para esse problema. Trata-se de sua Antropologia do Ponto de Vista Pragmático (KANT, 1979). E parece mesmo que a Antropologia Pragmática de Kant é para ele o sucedâneo de uma psicologia empírica inviável como ciência do mundo interno. O que significa, então, pensar a psicologia a partir da "Antropologia Pragmática"?

Além de traduzir esse texto de Kant para o francês, Michel Foucault escreve uma introdução de 128 páginas intitulada Introduction à l'anthropologie de Kant, que era, na verdade, uma tese complementar ao seu Doctorat des Lettres, do qual a tese principal era justamente a História da Loucura, defendida em 1961. A publicação dessa "Introdução", contudo, não foi autorizada por Foucault, permanecendo, infelizmente, de difícil acesso. ${ }^{6}$ Que a "Antropologia Pragmática”, de Kant parece muito presente nos artigos A Psicologia Científica de 1850 a 1950 (1996) e A Pesquisa Científica em Psicologia já seria suficiente para justificar nosso interesse na "Antropologia" de Kant. Toda a discussão a respeito da psicologia como "análise das significações da conduta humana" (em oposição à psicologia que se pretende ciência natural), na qual o homem é conhecido a partir de sua "liberdade fundamental", isto é, de sua livre "atividade espiritual" (FOUCAULT, 1996, p. 135-137), e que se encarna na história, faz ecoar a "Antropologia". Kant define sua "Antropologia Pragmática" em oposição ao conhecimento da natureza passiva do homem, ou o que ele chama de "conhecimento fisiológico do homem", que "tende à exploração disso que a 'natureza' faz do homem"; já o "conhecimento pragmático do homem" tende à exploração "disso que o homem, enquanto ser de livre atividade, faz ou pode e deve fazer de si próprio" (KANT, 1979, p. 11). Em lugar de considerar o homem como indivíduo fechado em sua experiência interna, como espectador passivo da natureza e de si, o homem é tomado como "cidadão do mundo" (KANT, 1979, p. 11), desde partida já em relação com o mundo e responsável pelo conhecimento que produz sobre ele (KANT, 1979, p. 11-12).

Mas a resposta à pergunta acima, com a qual nos ocuparemos nos próximos passos de nossa pesquisa, ainda sobre o problema da cientificidade da psicologia, seria incompleta se não fossem considerados outros textos de Kant sobre a história, tais como Idéia de uma história Universal do Ponto de Vista Cosmopolita (1784) e Conflito das Faculdades (1798), nos quais é discutido justamente a separação do dado da natureza do exercício da liberdade do homem. É neles e principalmente na "Antropologia Pragmática" de Kant que encontramos as balizas teóricas que seguiremos na seqüência deste artigo e que parecem justificar a aposta nessa orientação. 
Avançamos, porém, que pensar a psicologia a partir dessas referências kantianas significaria, então, retomar a psicologia como ciência singular, que assume positivamente sua historicidade, em lugar de pretender-se uma ciência da natureza, como a física, a química ou mesmo a meteorologia; que na história seu objeto ganha corpo, se espacializa - condição que Kant exigia para se ultrapassar o mero subjetivismo, relativo aos estados acessíveis apenas em primeira pessoa, no sentido interno e sua forma temporal. Mas significa, sobretudo, remeter a psicologia à dimensão ética do homem, na relação com seus pares, como “cidadão do mundo", à sua responsabilidade na constituição disso que a natureza não determinou, mas que a história produziu. Se a física se ocupa com o mundo da natureza, aí incluindo-se a fisiologia, ou, nos termos de Kant, a "antropologia fisiológica", que se ocuparia com o que de natural é dado ao homem (constituindo a passividade de seu corpo, senão ainda do seu mundo mental), a "Antropologia Pragmática" deve ocupar-se com o exercício da livre atividade do homem e sua expressão no mundo, em sua "conduta"7. Um tal conhecimento em lugar de encerrar o homem em uma natureza, abre, ao contrário, sua existência no mundo, para a o exercício de uma atividade que se desdobra na história como invenção.

\section{Notas}

1 A rigor, não apenas o conhecimento passa a ser entendido como condicionado pelas faculdades ou poderes propriamente humanos, mas também a moral. Tanto na produção do conhecimento quanto na legislação de sua conduta, é o homem que, nos limites de seus poderes, assume a responsabilidade.

2 Weber (professor de anatomia) e Fechner (professor de física) demonstraram justamente que as diferenças que percebemos em nossa experiência das coisas eram devidas não às próprias coisas, mas ao equipamento sensorial do homem. Cf.: Capítulo II da "História da Psicologia Experimental" de E. Boring e Capítulo XVI de "Os Grandes Experimentos em Psicologia" de Henry Garret. Sobre a investigação psicofísica das funções mentais, cf. Capítulo III de "Elementos de Psicofísica" (Vol. 1) de G. Fecnher $(1860,1966)$ das funções mentais e a investigação fisiológica.

3 O projeto kantiano de fundamentação metafísica da ciência e da moral é extensamente discutido e criticado em um outro texto nosso (GOMES, 2002).

4 O empenho em se impor como saber científico identifica-se não somente na fundação da psicologia experimental por Wundt. Seja como propedêutica às ciências, seja como ciência ela própria, a psicologia sempre se empenhou em ser científica, mesmo que concluamos que não tenha logrado o êxito pretendido. Quando as grandes escolas em psicologia, tais como o Gestaltismo, o Behaviorismo, a Psicologia Genética, a Escola Russa, além das mais recentes ciências da cognição, criticam umas às outras, é sempre visando a uma maior objetividade.

5 Evitaremos a discussão relativa aos "aspectos cognitivos e não-cognitivos" da ciência (CHALMERS, 1994, p. 110) e à epistemologia francesa em voga mais recentemente, remetendonos às conclusões de A. Chalmers, (1994, Cap. 6, 7 e 8).

6 Um comentário instrutivo sobre esse texto de Foucault encontra-se disponível em "Passagens: estudos sobre a filosofia de Kant", no artigo "Foucault, leitor de Kant: da Antropologia à ontologia do presente", de R. Lessa (2003), onde encontramos ainda indicação bibliográfica da "Introdução à Antropologia Pragmática": Bibliothèque de la Sorbonne, microfilme sob a Côte FB506.

7 Desnecessário seria enfatizar a distância que separa essa orientação da doutrina determinista do Behaviorismo, segundo a qual a "conduta" do homem continua o determinismo da natureza, no qual é o acaso, e não a liberdade, a mola da transformação, na evolução ou na história da civilização. De qualquer modo, é curioso notar que também em Kant a "conduta" permite superar os impasses de uma ciência que só pode abordar seu objeto em primeira pessoa: a observação da "conduta" é, então, o substituto de uma observação de si ("Selbstbeobachtung") ou introspecção. 


\section{REFERÊNCIAS}

BORING, E. Historia de la psicología experimental. México, D. F.: Editorial Trillas, 1950/1978.

CHALMERS, A. A fabricação da ciência. São Paulo: Ed. da Unesp, 1994.

FECHNER, G. Elements of Psychophysics. New York: Holt, Finehart and Winston, 1966.

FOUCAULT, M. La psychologie de 1850 à 1950. In: Dits et écrits. Paris: Éditions Gallimard, 1994a. . La recherche scientifique et la psychologie. In: . Dits et écrits. Paris: Éditions Gallimard, 1994b.

GARRET, H. Grandes experimentos em Psicologia. São Paulo: Ed. Nacional, 1959.

GOMES, A. A filosofia não-subjetivista de Hume: uma crítica à leitura kantiana do empirismo. 2002. Tese (Doutorado)-IFCS/UFRJ, Rio de Janeiro, 2002.

KANT, I. Anthropologie du point de vue pragmatique. Paris: Vrin, 1979.

Flammarion, 1990.

. Le Conflit des facultés in Kant: opuscules sur l'histoire. Paris: . La critique de la raison pure. Paris: Aubier, 1997.

. Idée d'une histoire universelle au point de vue cosmopolitique. In: . Kant: opuscules sur l'histoire. Paris: Flammarion, 1990.

Editorial, 1989.

. Principios metafísicos de la ciencia de la naturaleza. Madrid: Alianza

LESSA, R. Foucault, leitor de Kant: da antropologia à ontologia do presente. Passagens: estudos sobre a filosofia de Kant, 2003.

RIBOT, Th. La psychologie anglaise contemporaine (École Expérimental). Paris: Félix Acan, 1907.

TERRA, R. Passagens: estudos sobre a filosofia de Kant. Rio de Janeiro: Ed. da UFRJ, 2003.

Recebido em novembro/2004 Aceito em maio/2005 
